\title{
The effect of the daily intake of inulin on fasting lipid, insulin and glucose concentrations in middle-aged men and women
}

\author{
Kim G. Jackson*, Gary R. J. Taylor, Anna M. Clohessy and Christine M. Williams \\ Hugh Sinclair Unit of Human Nutrition, Department of Food Science and Technology, University of Reading, Whiteknights, \\ Reading RG6 6AP, UK
}

(Received 28 August 1998 - Revised 8 February 1999 - Accepted 12 March 1999)

\begin{abstract}
The present study was carried out to examine the effect of the daily intake of $10 \mathrm{~g}$ inulin on fasting blood lipid, glucose and insulin levels in healthy middle-aged men and women with moderately raised total plasma cholesterol (TC) and triacylglycerol (TAG) levels. This study was a doubleblind randomized placebo-controlled parallel study in which fifty-four middle-aged subjects received either inulin or placebo for a period of 8 weeks. Fasting blood samples were collected before the supplementation period (baseline samples 1 and 2, separated by 1 week) and at weeks 4 and 8 , with a follow-up at week 12 . Compared with baseline values, insulin concentrations were significantly lower at 4 weeks $(P<0.01)$ in the inulin group. There was a trend for TAG values, compared with baseline, to be lower in the inulin group at 8 weeks $(P<0.08)$ returning to baseline concentrations at week 12. On comparison of the inulin and placebo groups, the fasting TAG responses over the 8-week test period were shown to be significantly different $(P<0.05$, repeated measures ANOVA), which was largely due to lower plasma TAG levels in the inulin group at week 8 . The percentage change in TAG levels in the inulin group during the 8-week study was shown to correlate with the initial TAG level of the subjects $\left(r_{\mathrm{s}}-0.499, P=0.004\right)$. We therefore conclude that the daily addition of $10 \mathrm{~g}$ inulin to the diet significantly reduced fasting insulin concentrations during the 8-week test period and resulted in lower plasma TAG levels, particularly in subjects in whom fasting TAG levels were greater than $1.5 \mathrm{mmol} / \mathrm{l}$. These data support findings from animal studies that fructans influence the formation and/or degradation of TAG-rich lipoprotein particles, and the insulin data are also consistent with recent studies showing attenuation of insulin levels in fructan-treated rats.
\end{abstract}

Fructans: Inulin: Triacylglycerol: Insulin

Fructans (e.g. inulin and oligofructose (OFS)) are naturallyoccurring non-structural storage carbohydrates found in many vegetables, including onion, asparagus (Asparagus officianalis), Jerusalem artichoke (Helianthus tuberosus) and chicory (Cichorium intybus) root (Dyssler \& Hoffem, 1995). Inulin is currently found as a food component of bread, baked goods, yoghurt and ice-cream because it displays gelling and thickening properties and helps to improve the mouthfeel and appearance of lower-energy products (Dyssler \& Hoffem, 1995). In Europe the estimated intake of fructans is between 2 and $12 \mathrm{~g} / \mathrm{d}$ (Van Loo et al. 1995).

Recent evidence has highlighted not only total plasma cholesterol (TC) but also plasma triacylglycerol (TAG) as lipid risk factors for CHD (Zilversmit, 1995). This has generated a lot of interest, since studies in rats have shown markedly reduced fasting TC and TAG concentrations when diets containing significant amounts of OFS (for example, 50-200 g/kg rat chow) are fed (Roberfroid, 1993). Fructans are non-digestible carbohydrates which are fermented by the gut microflora, in particular, bifidobacteria and lactobacilli (Gibson \& McCartney, 1998). Early work suggested that the mechanism of action of OFS was associated with the modulation of de novo cholesterol synthesis by short-chain fatty acids produced by the gut microflora during the fermentation process (Demigné et al. 1995). Recent evidence has suggested that the TAG-lowering effect of OFS occurs via reduction in VLDL-TAG secretion from the liver as a result of the reduction in the activity of lipogenic enzymes, and in the case of fatty acid synthase (EC 2.3.1.85), via modification of lipogenic gene expression (Delzenne \& Kok, 1998). However, very little is known about the action of fructans in human subjects; in the studies conducted, inconsistent findings with respect to changes in blood lipids have been observed (Table 1). In studies with 


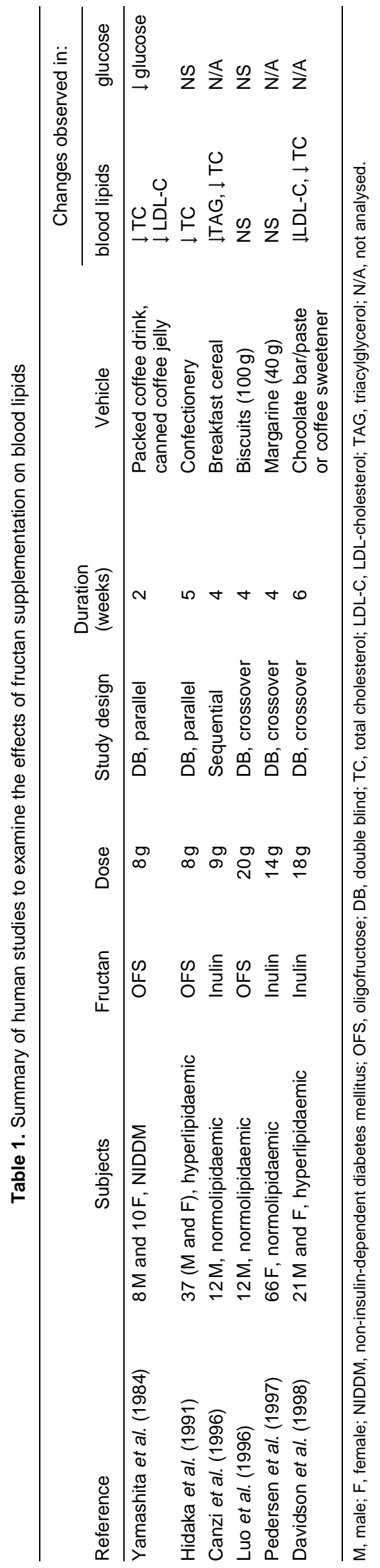

individuals with raised blood lipids, significant decreases in fasting TC and LDL-cholesterol (LDL-C) were observed, although there were no significant changes in TAG levels (Yamashita et al. 1984; Hidaka et al. 1991; Davidson et al. 1998). In normolipidaemic volunteers, only one study has demonstrated significant changes in fasting TAG $(-27 \%)$ and TC $(-5 \%)$ levels with inulin (Canzi et al. 1995). However, more recently, Luo et al. (1996) and Pedersen et al. (1997) have reported no effect of OFS or inulin treatment on blood lipids in young healthy subjects.

Recent studies in animals have demonstrated significantly lower blood insulin and glucose concentrations in rats fed with OFS (Kok et al. 1998). However, very little is known about the effect of inulin on blood glucose and insulin concentrations in human subjects. Of the supplementation studies conducted, a significant reduction in blood glucose was observed in non-insulin-dependent diabetic subjects (Yamashita et al. 1984) and a trend for a reduction in glucose was observed in hyperlipidaemic subjects (Hidaka et al. 1991) in response to OFS. A study investigating the effect of test meals containing OFS on blood glucose, insulin and C-peptide levels in healthy adults showed a trend for lower glycaemic responses and peak insulin levels following the OFS-enriched meals (Rumessen et al. 1990).

The aim of the present study was to examine the effects of the daily intake of inulin on blood lipids, glucose and insulin in healthy middle-aged men and women with moderately raised TC and TAG levels. The study was designed as a placebo-controlled parallel study and volunteers were randomized according to their sex, age, BMI and fasting plasma TC and TAG levels to receive either inulin or placebo for a period of 8 weeks. Inulin in a free form (white powder in sachets) was used as a vehicle to ensure optimal compliance without any significant alteration to the normal daily diet of the subjects.

\section{Subjects and methods}

\section{Subjects}

Fifty-four healthy, middle-aged men and women with moderately raised fasting plasma TC and TAG levels, a mean age of 52.2 (SD 9.5) years and BMI 26.4 (SD 3.2) kg/ $\mathrm{m}^{2}$ were recruited. The subjects all satisfied the following inclusion criteria: they were all between 35 and 65 years old with a BMI of between 20 and $32 \mathrm{~kg} / \mathrm{m}^{2}$. They did not have any history of heart disease, diabetes or any other endocrine or liver diseases. Their level of aerobic exercise was less than three sessions of $30 \mathrm{~min} /$ week and their level of alcohol intake was less than 30 units/week. They were not taking any medication for the treatment of hyperlipidaemia or any drug treatment which would affect their plasma lipid levels. They were not trying to lose weight, taking antibiotics before the study or taking dietary fatty acid supplements. The subjects were recruited following screening of fasting plasma TAG $(1.2-3.0 \mathrm{mmol} / \mathrm{l})$, TC $(5.5-8.0 \mathrm{mmol} / \mathrm{l})$ and glucose $(<6.2 \mathrm{mmol} / \mathrm{l})$ levels, haemoglobin level $(>130 \mathrm{~g} / \mathrm{l})$ and normal liver function tests.

The study was approved by the ethics committee of the University of Reading and all volunteers gave informed consent at the beginning of the study. 


\section{Study design}

The study was performed as a double-blind randomized placebo-controlled parallel study in which fifty-four subjects received either $10 \mathrm{~g}$ inulin (Raftiline HP Gel; Raffinerie Tirlemontoise (ORAFTI), Tienen, Belgium) or placebo (maltodextrin, Paselli SA2; AVEBE, The Netherlands) for a period of 8 weeks. Maltodextrin was chosen as the placebo because it displays similar physical properties to inulin (e.g. similar taste and dissolves in hot and cold fluids), it is fully digestible, not available for fermentation by the gut microflora and has an energy value similar to that of inulin. Subjects were randomized using stratified randomization with minimization for sex, age, BMI and fasting TAG using data obtained at screening. Although stratified randomization was also attempted for TC, this could not be fully achieved if the plasma TAG values (the primary blood lipid outcome marker for the study) were also to be comparable for both groups. For this reason there were small but significant differences in the TC values for the two groups at the beginning of the study $(P<0 \cdot 05)$. Both inulin and placebo were supplied to the subjects in the form of sachets containing white powder and they were instructed to add two sachets (each sachet $5 \mathrm{~g}$ ) to water, tea, coffee, orange juice, soup, breakfast cereal or yoghurt. Sachets were stored at room temperature until the day of consumption. The subjects were provided with sachets in 4-week batches, and at weeks 4 and 8 the subjects returned all of their used sachets and reported any missed sachets to an investigator. Compliance and gastrointestinal symptoms were assessed using a questionnaire which was filled in by all of the subjects at week 8 of the study. For the question concerning changes in gastrointestinal symptoms experienced during the study, the subjects were asked to tick a number of symptoms including indigestion, stomach cramps, stomach bloating, flatulence, looser stools and diarrhoea.

Fasting blood samples were collected following a $12 \mathrm{~h}$ overnight fast. Samples were collected before the supplement was given (two baseline samples separated by 1 week), at 4 and 8 weeks and at week 12 (follow-up sample 4 weeks after completion of the supplementation period). There were no significant differences for any of the variables measured between blood samples collected at baselines 1 and 2 for either the inulin or the placebo group and so these values were averaged and termed mean baseline for easier interpretation of the results in the tables and figures.

\section{Plasma separation and analytical methods}

Blood samples were collected into EDTA-coated vacutainers (HM \& S, Northampton, Northants., UK) and a portion of blood was immediately removed and placed into a fluoride oxalate tube (L.I.P, Shipley, W. Yorks., UK) for the analysis of glucose. The blood samples were centrifuged at $1700 \mathrm{~g}$ for $10 \mathrm{~min}$ and plasma was divided into portions which were placed into the appropriate LP3 tube (L.I.P.) before storage at $-20^{\circ}$ until analysis. All samples for each subject were analysed within a single batch.

Measurement of total cholesterol, HDL-cholesterol, triacylglycerol, apolipoprotein B, apolipoprotein A-I and glucose. TC, HDL-cholesterol (HDL-C), TAG, apolipoprotein (apo) B, apoA-I and glucose in plasma were analysed using an IL Monarch centrifugal analyser (Instrumentation Laboratory, Warrington, Ches., UK). TAG was measured using a lipase (EC 3.1.1.3)-glycerol lipase ( $E C$ 2.7.1.30) method (Instrumentation Laboratory), glucose concentrations measured using a hexokinase (EC 2.7.1.1) method (Instrumentation Laboratory), TC and HDL-C using a cholesterol esterase (EC 3.1.1.13)-cholesterol oxidase (EC 1.1.3.6) method (Instrumentation Laboratory). HDL-C concentration was determined following precipitation of lower-density lipoproteins with a dextran- $\mathrm{MgCl}_{2}$ reagent (McNamara et al. 1994). LDL-C was calculated using the Friedewald formula (Friedewald et al. 1972). ApoB and apoA-I were measured using immunoturbidimetric methods using specific antibodies (Instrumentation Laboratory). The LDL-C:HDL-C ratio was determined by dividing individual LDL-C concentrations by those for the HDL-C concentrations and calculating the mean and standard deviation for each of the fasting timepoints. The intra-assay $\mathrm{CV}$ for the analyses performed on the centrifugal analyser were $2.1 \%$ for TC, $2.0 \%$ for TAG, $4.5 \%$ for glucose and $4.5 \%$ for apoB and apoA-I.

Measurement of insulin. Plasma insulin was measured using a specific enzyme-linked immunosorbent assay incorporating monoclonal antibodies (Dako Ltd, High Wycombe, Bucks., UK). The intra-assay CV for insulin was $4.5 \%$. The glucose : insulin ratio was determined by dividing individual glucose concentrations by those for the insulin concentrations and calculating the mean and standard deviation for each of the fasting timepoints.

\section{Statistical analysis}

Repeated measures ANOVA was performed using the Statistical Package for the Social Sciences (SPSS; SPSS Inc., Chicago, IL, USA) to determine if any changes had occurred in any of the variables measured over time within the inulin and placebo groups. Statistically significant differences were then located using a post hoc test (StudentNewman-Keuls multiple comparisons post test). A onewithin subject, one-between subject repeated measures ANOVA was used to compare the differences in the responses of the subjects in the inulin and placebo groups over time. In the tables, results are presented as mean values and standard deviations and in the figures, results are presented as mean values with their standard errors. Data were checked for normality and log transformed before statistical analysis was preformed. This was found necessary in the case of insulin. Spearman's rank order correlation was used to evaluate relationships between baseline TAG and percentage changes in TAG with treatment. Values of $P<0.05$ are taken as significant.

\section{Results}

Supplementation periods of 8 weeks were successfully completed by all of the fifty-four subjects and the characteristics of the inulin and placebo groups are shown in Table 2. There were no significant changes in body weight during the supplementation period in either the inulin or placebo group. 
Table 2. Characteristics of subjects in the inulin and placebo groups following randomization

(Mean values and standard deviations for twenty-seven subjects)

\begin{tabular}{lccccc}
\hline & \multicolumn{2}{c}{ Inulin group } & & \multicolumn{2}{c}{ Placebo group } \\
\cline { 2 - 3 } & Mean & SD & & Mean & SD \\
\hline Age (years) & 52.6 & 8.6 & & 51.9 & 10.5 \\
BMl (kg/m ${ }^{2}$ ) & 26.5 & 3.6 & & 26.1 & 2.8 \\
Fasting lipids (mmol/l) & & & & \\
TC & 5.8 & 1.1 & & $6.3^{*}$ & 0.8 \\
TAG & 1.4 & 0.6 & & 1.4 & 0.4 \\
\hline
\end{tabular}

TC, total cholesterol; TAG, triacylglycerol.

Mean value was significantly higher than that for the inulin group: ${ }^{\star} P<0.05$.

Repeated measures ANOVA showed an effect of time on insulin levels in the inulin group and post-hoc analysis indicated a significant decrease in fasting insulin concentrations between baseline and week $4(P<0 \cdot 01)$. The insulin concentrations showed a tendency to remain lower than baseline levels at week 8 and then returned to baseline concentrations 4 weeks after completion of the study (week 12; Fig. 1). There were no significant differences in insulin concentrations over the 8-week period in the placebo group (Fig. 1). No significant differences were observed in fasting glucose concentrations or glucose : insulin ratio for either the inulin or placebo group over the 8-week supplementation period (Table 3).

Stratified randomization was successful for plasma TAG so that there were no significant differences between the groups at baseline (Table 2). However, there was a tendency for fasting TAG values to be lower at 8 weeks compared with baseline $(P<0.08)$ in the inulin-treated group (Fig. 2$)$. A one-within subject, one-between subject repeated measures ANOVA showed the effect of treatment over time on fasting plasma TAG responses to be statistically significantly different $(P<0 \cdot 05)$. Fig. 2 shows the fasting plasma TAG concentrations for both groups over the period of the study. Spearman's rank order correlation demonstrated that the subjects' initial TAG concentrations (mean baseline) were significantly correlated with the percentage change in TAG concentrations over the 8-week supplementation period in the inulin group $\left(r_{\mathrm{s}}-0 \cdot 499, P=0 \cdot 004\right)$. However, this relationship was not observed for the subjects in the placebo group $\left(r_{\mathrm{s}}-0 \cdot 233, P=0 \cdot 121 ; \mathrm{Fig} .3\right)$. There were no significant differences, from baseline values for the fasting TC, HDL-C, LDL-C, apoB, apoA-I or LDL-C: HDL-C values over the 8 -week period for either the inulin or placebo groups (Table 3). TC values were significantly higher in the placebo group at baseline due to incomplete stratified randomization $(P<0.05)$; values remained higher throughout the study.

\section{Discussion}

The present study was designed to examine the effects of the daily intake of $10 \mathrm{~g}$ inulin on fasting blood lipids, glucose and insulin levels in subjects with blood lipids in the upper end of the normal range. A significant decrease in plasma insulin level was observed after 4 weeks of inulin supplementation, and this remained lower than baseline levels at 8 weeks, returning to baseline values after completion of the dietary intervention period (week 12). However, no effect of inulin treatment on fasting blood glucose concentrations was observed in the present study. Very little is known about the effects of inulin on fasting plasma insulin and glucose levels, although a recent animal study has shown attenuation of both insulin and glucose concentrations following long-term OFS feeding in rats. The effects were attributed to the actions of OFS on secretion of the gut hormones glucose-dependent insulinotropic polypeptide and glucagon-like peptide 1 (Kok et al. 1998). A study carried out in non-insulin-dependent diabetic subjects (Yamashita et al. 1984) demonstrated a significant lowering of blood glucose levels with OFS, however, very little is known about the effects of fructans, especially inulin, in normal healthy people consuming a typical Western-style diet.

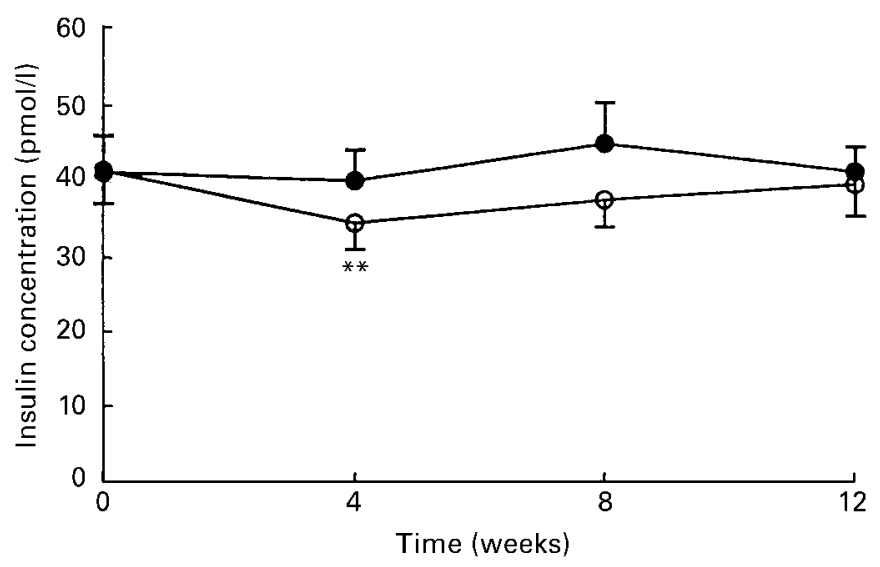

Fig. 1. Fasting plasma insulin concentrations in groups of subjects receiving inulin (-○-) or placebo (-๑-) for 8 weeks. Samples were taken at baseline (week 0), week 4 and week 8 of the supplementation period, and a follow-up sample was taken at week 12 . Blood samples were collected following a $12 \mathrm{~h}$ overnight fast. Values are means for twenty-seven volunteers in each group, with their standard errors represented by vertical bars. Mean value was significantly different from that for the same group at baseline: ${ }^{* \star} P<0.01$. 
Table 3. Fasting plasma lipid and hormone levels in subjects receiving $10 \mathrm{~g}$ inulin or a placebo daily for 8 weeks (Mean values and standard deviations for twenty-seven subjects)

\begin{tabular}{|c|c|c|c|c|c|c|c|c|}
\hline & \multicolumn{2}{|c|}{ Mean baseline } & \multicolumn{2}{|c|}{ Week 4} & \multicolumn{2}{|c|}{ Week 8} & \multicolumn{2}{|c|}{ Week 12} \\
\hline $\begin{array}{l}\text { TC (mmol/l) } \\
\text { Inulin } \\
\text { Placebo }\end{array}$ & $\begin{array}{l}5.86 \\
6.43\end{array}$ & $\begin{array}{l}1.00 \\
0.79\end{array}$ & $\begin{array}{l}6.07 \\
6.53\end{array}$ & $\begin{array}{l}0.99 \\
1.08\end{array}$ & $\begin{array}{l}5.90 \\
6.46\end{array}$ & $\begin{array}{l}0.97 \\
0.91\end{array}$ & $\begin{array}{l}5.87 \\
6 \cdot 23\end{array}$ & $\begin{array}{l}0.90 \\
0.75\end{array}$ \\
\hline $\begin{array}{l}\text { TAG (mmol } \\
\text { Inulin } \\
\text { Placebo }\end{array}$ & $\begin{array}{l}1.46 \\
1.40\end{array}$ & $\begin{array}{l}0.55 \\
0.40\end{array}$ & $\begin{array}{l}1.50 \\
1.49\end{array}$ & $\begin{array}{l}0.53 \\
0.54\end{array}$ & $\begin{array}{l}1.29 \\
1.59\end{array}$ & $\begin{array}{l}0.35 \\
0.58\end{array}$ & $\begin{array}{l}1.45 \\
1.51\end{array}$ & $\begin{array}{l}0.61 \\
0.54\end{array}$ \\
\hline $\begin{array}{l}\text { LDL-C (mm } \\
\quad \text { Inulin } \\
\text { Placebo }\end{array}$ & $\begin{array}{l}3.97 \\
4.55\end{array}$ & $\begin{array}{l}0.86 \\
0.92\end{array}$ & $\begin{array}{l}4.06 \\
4.57\end{array}$ & $\begin{array}{l}0.91 \\
1.17\end{array}$ & $\begin{array}{l}4.00 \\
4.43\end{array}$ & $\begin{array}{l}0.85 \\
1.08\end{array}$ & $\begin{array}{l}3.85 \\
4.24\end{array}$ & $\begin{array}{l}0.76 \\
0.93\end{array}$ \\
\hline $\begin{array}{l}\text { LDL-C : HDL } \\
\quad \text { Inulin } \\
\text { Placebo }\end{array}$ & $\begin{array}{l}3.32 \\
3.88\end{array}$ & $\begin{array}{l}0.90 \\
1.26\end{array}$ & $\begin{array}{l}3.27 \\
3.84\end{array}$ & $\begin{array}{l}1.07 \\
1.39\end{array}$ & $\begin{array}{l}3.26 \\
3 \cdot 77\end{array}$ & $\begin{array}{l}1 \cdot 13 \\
1.55\end{array}$ & $\begin{array}{l}3.04 \\
3.65\end{array}$ & $\begin{array}{l}0.95 \\
1.45\end{array}$ \\
\hline $\begin{array}{l}\text { ApoA-I (mg } \\
\text { Inulin } \\
\text { Placebo }\end{array}$ & $\begin{array}{l}1193 \\
1242\end{array}$ & $\begin{array}{l}218 \\
271\end{array}$ & $\begin{array}{l}1253 \\
1240\end{array}$ & $\begin{array}{l}297 \\
274\end{array}$ & $\begin{array}{l}1165 \\
1222\end{array}$ & $\begin{array}{l}211 \\
236\end{array}$ & $\begin{array}{l}1160 \\
1202\end{array}$ & $\begin{array}{l}233 \\
262\end{array}$ \\
\hline $\begin{array}{l}\text { Insulin (pmo } \\
\text { Inulin } \\
\text { Placebo }\end{array}$ & $\begin{array}{l}41.5 \\
41.3\end{array}$ & $\begin{array}{l}22 \cdot 1 \\
24 \cdot 4\end{array}$ & $\begin{array}{l}34.4 \dagger \dagger \\
40.0\end{array}$ & $\begin{array}{l}17.9 \\
20.6\end{array}$ & $\begin{array}{l}37.5 \\
44.9\end{array}$ & $\begin{array}{l}18.3 \\
27.5\end{array}$ & $\begin{array}{l}39.6 \\
41.3\end{array}$ & $\begin{array}{l}21.5 \\
16.9\end{array}$ \\
\hline $\begin{array}{l}\text { Glucose (m } \\
\text { Inulin } \\
\text { Placebo }\end{array}$ & $\begin{array}{l}4.73 \\
4.92\end{array}$ & $\begin{array}{l}0.51 \\
0.39\end{array}$ & $\begin{array}{l}4.69 \\
4.81\end{array}$ & $\begin{array}{l}0.63 \\
0.49\end{array}$ & $\begin{array}{l}4.84 \\
4.99\end{array}$ & $\begin{array}{l}0.51 \\
0.49\end{array}$ & $\begin{array}{l}4.73 \\
4.77\end{array}$ & $\begin{array}{l}0.45 \\
0.53\end{array}$ \\
\hline $\begin{array}{l}\text { Glucose: ins } \\
\text { Inulin } \\
\text { Placebo }\end{array}$ & $\begin{array}{l}151.5 \\
155.7\end{array}$ & $\begin{array}{l}72.5 \\
65.0\end{array}$ & $\begin{array}{l}176 \cdot 1 \\
149 \cdot 8\end{array}$ & $\begin{array}{r}101.6 \\
72.5\end{array}$ & $\begin{array}{l}158.9 \\
161.5\end{array}$ & $\begin{array}{r}76.8 \\
132.2\end{array}$ & $\begin{array}{c}177.8 \\
148.2\end{array}$ & $\begin{array}{r}184.6 \\
99.9\end{array}$ \\
\hline
\end{tabular}

TC, total cholesterol; TAG, triacylglycerol; HDL-C, HDL-cholesterol; LDL-C, LDL-cholesterol; apo, apolipoprotein.

Difference between treatments was statistically significant: ${ }^{*} P<0.05$ (repeated measures ANOVA).

Mean value was significantly different from the corresponding baseline value: $\dagger \uparrow P<0.01$.

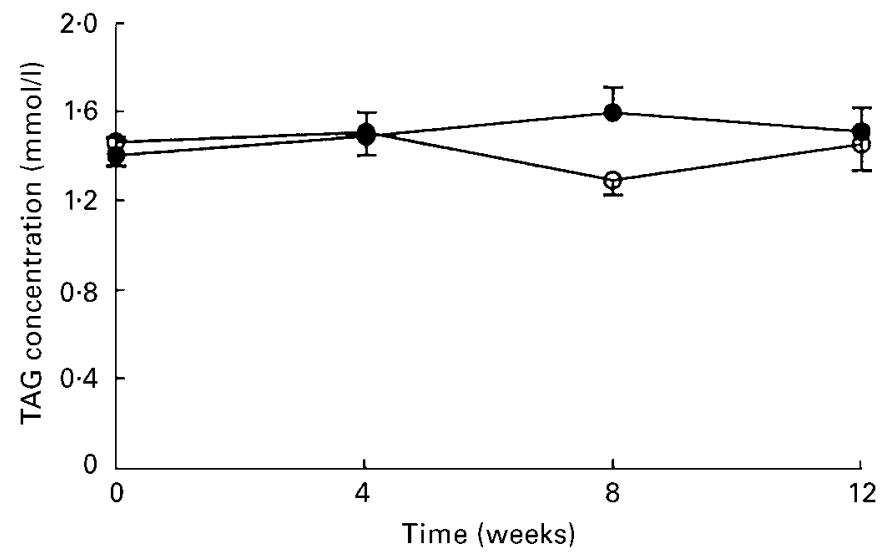

Fig. 2. Fasting plasma triacylglycerol (TAG) responses in groups of subjects receiving inulin (-O-) or placebo (-๑-) for 8 weeks. Samples were taken at baseline (week 0 ), week 4 and 8 of the supplementation period, and a follow-up blood sample was taken at week 12 . Blood samples were collected following a $12 \mathrm{~h}$ overnight fast. Values are means for twenty-seven volunteers in each group, with their standard errors represented by vertical bars. There was a significant difference between treatments (inulin and placebo) $(P<0.05$, repeated measures ANOVA). 

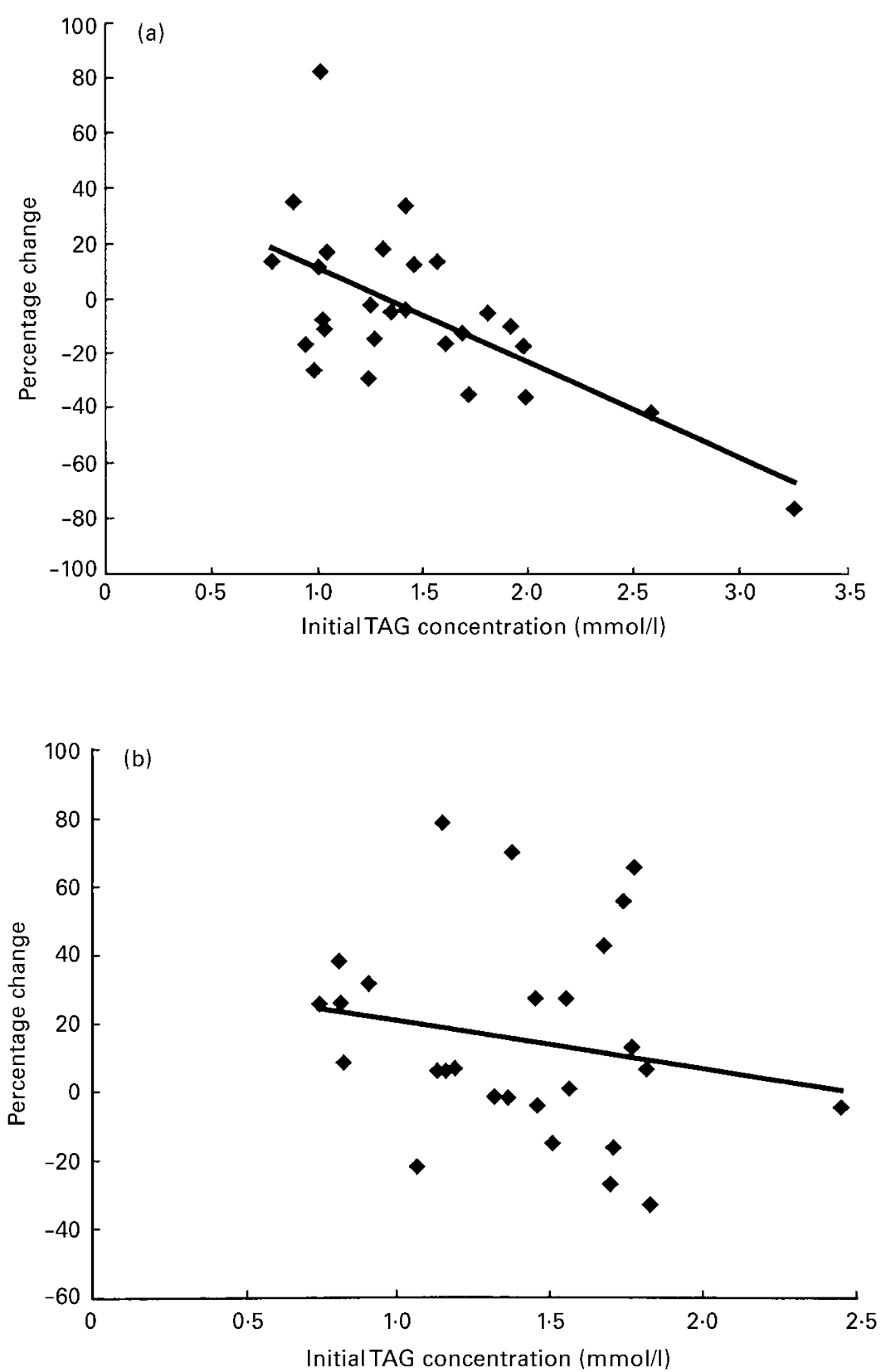

Fig. 3. Relationship between baseline plasma triacylglycerol (TAG) level (mean of two samples) and percentage change in TAG level during an 8week intervention with (a) $10 \mathrm{~g}$ inulin/d $\left(r_{s}-0.449, P=0.004\right)$ and (b) placebo $\left(r_{s}-0.233, P<0.121\right)$.

Six studies which have investigated effects of fructans on blood lipid levels in human subjects have generated inconsistent findings (Table 1). Of the studies conducted, significant reductions have been observed in subjects with raised TC and TAG levels, including subjects with noninsulin-dependent diabetes mellitus (Yamashita et al. 1984) and hyperlipidaemia (Hidaka et al. 1991; Davidson et al. 1998), but only one study has shown significant reductions in TC and TAG in normolipidaemic subjects (Canzi et al. 1995). In the studies of Pedersen et al. (1997) and Luo et al. (1995), young healthy subjects with relatively low TC and TAG concentrations were recruited and this may have contributed to the lack of effects observed with both inulin and OFS supplementation.
The positive effects of inulin on TAG in the present study may be the result of a number of factors employed in the study design. The subjects were chosen for their moderately raised TC and TAG levels, and, although there was a change in TAG in the group as a whole, there were a number of nonresponders who maintained their TAG levels throughout the 8 -week period. The significant relationship between subjects' initial TAG concentration and percentage change in TAG levels over the study period $\left(r_{\mathrm{s}}-0.499, P=0.004\right)$ lends support to the hypothesis that the initial TAG levels could be important in determining the degree of the TAG response to inulin. The lack of response in some individuals may be a result of their being less responsive to inulin, variations in their background diet or non-compliance with the study 
protocol. Speculation as to possible reasons for variability in response would be aided by a better understanding of the mechanism of action of inulin on blood TAG levels. Present data from animal studies suggest inhibition of de novo lipogenesis as the primary mode of action of fructans, and if this is the case, more modest or inconsistent effects might be expected in human subjects, in whom de novo lipogenesis is extremely low or variable depending on background diet.

The length of the supplementation period used in the present study may be another factor for the positive findings of inulin on TAG levels. This study was conducted over a period of 8 weeks compared with 2, 4, 5 and 6 weeks in the dietary studies described in Table 1 . In the present study fasting TAG concentrations at week 4 were comparable with baseline values, but a trend for a significant decrease in the inulin group compared with baseline levels $(P<0.08)$ was observed at week 8 , with the decline occurring sometime between the measurements at 4 and 8 weeks. Therefore lack of lipid lowering noted in the studies of Pedersen et al. (1997) and Luo et al. (1995) may have been due to insufficient duration of supplementation. In the present study, follow-up blood samples were taken at week 12 (4 weeks after completion of the supplementation period) by which time the concentrations of both TAG and insulin had returned to baseline values, supporting the conclusion that inulin feeding may be responsible for these findings. It also suggests that 4 weeks is a sufficient wash-out period for subjects consuming $10 \mathrm{~g}$ inulin daily. This is supported by Gibson et al. (1995) who reported that the number of days required for the population of bifidogenic bacteria to return to pre-supplementation numbers was determined by the dosage, with $1 \mathrm{~d}$ being necessary for each gram of inulin used per day. No significant effect of inulin supplementation on other lipid variables, including plasma TC, LDL-C or HDL-C, apoB and apoA-I levels, were observed in the present study. This is in line with the observed effects of inulin on lipid levels in animals in which the predominant effect is on TAG rather than cholesterol concentrations. However, in view of the large number of variables measured in the present study, it is possible that statistically significant findings with respect to TAG have arisen by chance, due to the relatively large number of statistical comparisons employed.

The amounts of fructans used in the human studies in Table 1 varied between 9 and $20 \mathrm{~g}$ and the types of vehicles used to increase their amount in the diet differed. Inulin in its free form (powder) was used in the present study to ensure optimal compliance and prevent any changes in body weight or the need for dietary advice. In the study of Luo et al. (1995), $100 \mathrm{~g}$ biscuits were eaten every day and in the study of Pedersen et al. (1997), $40 \mathrm{~g}$ margarine was consumed which may have contributed to the negative findings in blood lipids. The amounts of fructans used in the human studies are small compared with those used in animal (rat) studies and it is not known whether, at the levels used in human studies, significant effects would be observed in animals (Delzenne et al. 1993).

In conclusion, the addition of $10 \mathrm{~g}$ inulin to the daily diet of subjects with moderately raised blood lipids significantly reduced insulin levels and in comparison with the placebo group, resulted in lower plasma TAG concentrations. The degree of the plasma TAG reduction was greater in subjects with high plasma TAG levels at baseline. The daily dosage used in this study did not elicit significant gastrointestinal symptoms and the vehicle used ensured optimal compliance from our subjects. This study supports findings in animals that fructans may influence the formation and degradation of TAG-rich lipoprotein particles. Since the observed changes in fasting TAG were small with considerable heterogeneity so that prolonged feeding with high doses may be required to elicit more consistent effects. The significant finding of attenuating effects of inulin on insulin levels has not previously been reported in healthy human subjects and requires further investigation.

The design of future studies to investigate the effect of fructans in human subjects should consider the choice of subjects, length of supplementation period and type of vehicle used to increase the intake of fructans in the diet as these variables may influence the outcome of the study.

\section{Acknowledgements}

We are very grateful to Raffinerie Tirlemontoise (ORAFTI), Tienen, Belgium for supporting this study. The authors also wish to thank Dr Paul Robinson, Mrs Jan Luff and Miss Clare Thomas for their assistance.

\section{References}

Canzi E, Brighenti FB, Casiraghi MC, Del Puppo E \& Ferrari A (1995) Prolonged consumption of inulin in ready-to-eat breakfast cereals: effects on intestinal ecosystem, bowel habits and lipid metabolism. In COST 92, Workshop. Dietary Fibre and Fermentation in the Colon, Helsinki, pp. 280-284. Luxembourg: Office for Official Publications of the European Communities.

Davidson MH, Synecki C, Maki KC \& Drennen KB (1998) Effects of dietary inulin in serum lipids in men and women with hypercholesterolaemia. Nutrition Research 3, 503-517.

Demigné C, Morand C, Levrat M-A, Besson C, Moundras C \& Rémésey C (1995) Effect of propionate on fatty acid and cholesterol synthesis and on acetate metabolism in isolated rat hepatocytes. British Journal of Nutrition 74, 209-219.

Delzenne NM \& Kok N (1998) Effect of non-digestible fermentable carbohydrates on hepatic fatty acid metabolism. Biochemical Society Transactions 26, 228-230.

Delzenne NM, Kok N, Fiordaliso M-F, Deboyser DM, Goethals FM \& Roberfroid RM (1993) Dietary fructo-oligosaccharides modify lipid metabolism. American Journal of Clinical Nutrition 57, 820S.

Dysseler P \& Hoffem D (1995) Inulin, an alternative dietary fibre. Properties and quantitative analysis. European Journal of Clinical Nutrition 49, S145-S152.

Friedewald WT, Levy RI \& Fredrickson DS (1972) Estimation of the concentration of LDL cholesterol in plasma, without the use of the preparative ultracentrifuge. Clinical Chemistry 18, 499-502.

Gibson GR, Beatty ER, Wang X \& Cummings JH (1995) Selective stimulation of bifidobacteria in the human colon by oligofructose and inulin. Gastroenterology 108, 975-982.

Gibson GR \& McCartney AL (1998) Modification of gut flora by dietary means. Biochemical Society Transactions 26, 222-228.

Hidaka H, Tashiro Y \& Eida T (1991) Proliferation of bifidobacteria by oligosaccharides and their useful effect on human health. Bifidobacteria Microflora 10, 65-79. 
Kok NN, Morgan LM, Williams CM, Roberfroid MB, Thissen J-P \& Delzenne NM (1998) Insulin, glucagon-like peptide 1, glucose dependent insulinotropic polypeptide and insulin-like growth factor 1 as putative mediators of the hypolipidemic effect of oligofructose in rats. Journal of Nutrition 128, 1099-1103.

Luo J, Rizkalla SW, Alamowitch C, Boussairi A, Blayo A, Barry J-L, Laffitte A, Guyon F, Bornet FRJ \& Slama G (1996) Chronic consumption of short-chain fructooligosaccharides by healthy subjects decreased basal hepatic glucose production but had no effect on insulin-stimulated glucose metabolism. American Journal of Clinical Nutrition 63, 939-945.

McNamara JR, Huang C, Massov T, Leary ET, Warnick GR, Rubins HB, Robins SJ \& Schaefer EJ (1994) Modification of the Dextran- $\mathrm{Mg}^{2+}$ high-density lipoprotein cholesterol precipitation method for use with previously frozen plasma. Clinical Chemistry 40, 233-239.

Pedersen A, Sandström B \& van Amelsvoort JMM (1997) The effect of ingestion of inulin on blood lipids and gastrointestinal symptoms in healthy females. British Journal of Nutrition 78, 215-222.
Roberfroid M (1993) Dietary fiber, inulin and oligofructose: a review comparing their physiological effects. Critical Reviews in Food Science and Nutrition 33, 102-148.

Rumessen JJ, Bode S, Hamberg O \& Gudmand-Hoyer E (1990) Fructans of the Jerusalem artichokes: intestinal transport, absorption, fermentation, and influence on blood glucose, insulin, and C-peptide responses in healthy subjects. American Journal of Clinical Nutrition 52, 675681.

Yamashita K, Kawai K \& Itakura M (1984) Effects of fructooligosaccharides on blood glucose and serum lipids in diabetic subjects. Nutrition Research 4, 961-966.

Van Loo J, Coussement P, de Leenheer L, Hoebregs H \& Smits G (1995) On the presence of inulin and oligofructose as natural ingredients in the Western diet. Critical Reviews in Food Science and Nutrition 35, 525-552.

Zilversmit DB (1995) Atherogenic nature of triglycerides, postprandial lipaemia and triglyceride rich remnant lipoproteins. Clinical Chemistry 41, 153-158. 